\title{
REVIEW
}

\section{Regional studies and conceptual fuzziness: A critical review}

\author{
Muhammad Adil Rauf ${ }^{1^{*}}$ Olaf Weber ${ }^{1}$ \\ ${ }^{1}$ School of Environment, Enterprise and Development (SEED), Faculty of Environment, University of Waterloo, Waterloo, ON, Canada
}

\section{Check for updates}

Correspondence to: Muhammad Adil Rauf, School of Environment, Enterprise, and Development, Faculty of Environment, EV 3, University of Waterloo, 200 University Ave W, Waterloo, ON N2L 3G1, Canada; E-mail: adil.rauf@uwaterloo.ca

Received: April 5, 2021;

Accepted: April 30, 2021;

Published: May 6, 2021.

Citation: Rauf MA and Weber O. Regional studies and conceptual fuzziness: A critical review. Resour Environ Econ, 2021, 3(1): 251-262.

https://doi.org/10.25082/REE.2021.01.005

Copyright: (c) 2021 Muhammad Adil Rauf and Olaf Weber. This is an open access article distributed under the terms of the Creative Commons Attribution License, which permits unrestricted use, distribution, and reproduction in any medium, provided the original author and source are credited.

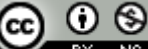

\begin{abstract}
Regional and spatial studies, such as urban planning, energy planning, and sustainable development, address the complexity of the inter-disciplinary relationship between subsystems and their components. Such research requires multidisciplinary concepts, varied lenses, and differentiating approaches and models to address the conflict between contextual sensitivity and universal applicability. This paper reviews the debate on the research approaches adopted in regional studies and initiated by researcher Ann Markusen, followed by a review of contemporary literature on fuzziness in qualitative research. Markusen evaluated the conceptual fuzziness, empirical evidence, and policy dimensions of regional studies based on three fundamental aspects of regional and urban development studies; strong contestation of phenomena, empirical evidence to support the concept, and collective action to deal with the problems under investigation. As highlighted by Markusen almost two decades ago, conceptual fuzziness and methodological weaknesses in qualitative research persist in interdisciplinary qualitative research. In this study, we have dissected the concept of fuzziness to distinguish between Inherited fuzziness derived from the configurational complexity of a case and bequeathed fuzziness that could be transferred ahead due to a researcher's methodological and perceptual weaknesses. Despite efforts to address the relevance, reliability, validity, and replicability of the qualitative research, the field is still facing challenges from conceptual bias, methodological and operational constraints, empirical weakness, and prejudiced interpretation.
\end{abstract}

Keywords: regional studies, spatial planning, fuzzy concepts, sustainability, research methods

\section{Introduction}

Interdisciplinary research, such as spatial planning, energy planning, housing and infrastructure, and sustainable development, requires multidisciplinary knowledge-sharing to address operational and policy issues [1]. Interdisciplinary research topics are sensitive to the socio-spatial context, and they need an emphasis on objectives, values, motivations, and an understanding of existing practices [2]. This contextual sensitivity and uniqueness make interdisciplinary fields highly uncertain and dynamic [3]. Consequently, many multidisciplinary research fields have adopted a system approach defining the configuration and relationships of system components to interpret complex interactions and explore multiple pathways and their respective outcomes [4].

From a multidisciplinary approach, sustainable urban development should create a synergy between socioeconomic and environmental systems and subsystems to achieve a cohesive and collaborative urban environment. This process needs to incorporate multiple components of sustainability into planning and development policies [5]. Consequently, the relationship between energy, the built environment, and functional organizations should integrate energy and spatial planning [6]. On the other hand, energy planning from an interdisciplinary perspective requires integrated decision-making based on hybrid information [7] that necessitates an evaluation of energy sources, technology, and operational alternatives [8]. Furthermore, it requires multiple criteria evaluation, ranking of alternatives, and critical trade-offs for sustainable decision making $[7,8]$. A long-term integrated energy planning involves holistic energy modeling capacitated to quantify multiple pathways to deal with the complex and evolving urban environment [9].

Similarly, regional and local development also relies on inter-disciplinary relationships, making it difficult to not only view from a singular disciplinary lens, concept, theory, and model but also unable to address both contextual sensitivity and universality [10]. This paper has conducted a review of methodological concerns in qualitative research in multidisciplinary studies such as spatial and regional planning. We have reviewed the literature, discussions, and debates that have come up in the past and present, highlighting methodological concerns related to fuzziness in qualitative research. We started with the review of the article published by Ann 
Markusen in 2003 [11, 12] and the debate that generated afterward. Ann Markusen (2003) [11, 12] critically reviewed the scholarly work in regional studies published between the mid-1970s and 2000. Markusen divided the study period into two eras: before and after the mid-1980s. Her review was based on the quality of research work conducted during these periods and highlighted the key differences in academic research approaches. She also discussed the dominating research approaches in regional studies before and after the mid-1980s. She highlighted the significance of the research outcomes with regard to their operationalization, policy relevance, and development [11,12]. Furthermore, we have reviewed three significant contributions from Arnoud Lagendiji, Jamie Peck, and Ray Hudson in response to Markusen's work. Subsequently, we have reviewed recent work on theoretical and methodological development in qualitative fuzziness to understand the concept of fuzziness and the evolving practices in qualitative research.

The primary outcome of this review article is that most of the methodological weaknesses in qualitative research highlighted almost two decades ago persist in interdisciplinary qualitative research. Despite efforts to address the relevance, reliability, validity, and replicability that the qualitative research field still faces today, challenges from conceptual bias, methodological and operational constraints, empirical weakness, and prejudice interpretation remain. However, distinguishing between the conceptual fuzziness inherited from the contextual vagueness and the fuzziness bequeathed by a researcher's methodological and perceptual weaknesses could help address the challenges mentioned earlier.

The remainder of the paper is structured as follows. We present Markusen's core arguments in the first half, followed by our analysis, summarizing the critical debate generated afterward. The second part presents the prevailing methodological practices in academia to assess the significance of the concerns raised by Markusen decades ago. The paper concludes with a detailed discussion on contemporary approaches and the conclusion.

\section{Markusen's regional studies and fuzzy concepts}

Markusen reviewed three bodies of regional studies: flexible specializations, world cities, and cooperative competition in industrial districts $[11,12]$. She evaluated the studies on the conceptual approach and empirical and policy dimensions of the problems investigated in each work $[11,12]$.

Markusen based her argument on three fundamental aspects of regional and urban development studies: contestation of phenomena, empirical evidence to support the concept, and collective action to deal with problems under investigation. According to her research, most of the work carried out after the mid-1980s to 2000 was uncontested and based on "fuzzy concepts" with no or minimum evidence [11,12]. Markusen grounded her criticism based on the implications of these studies and further discussed some of the reasons that led to such practices in regional studies. As per Markusen, the fuzzy concepts lack clarity primarily due to insufficient evidence and excessive reliance on a system rather than relationships between institutions, agents, and behaviors. Such contextual disconnect could lead to a difficulty in understanding and operationalizing theoretical concepts $[11,12]$. Furthermore, research conducted under operational constraints and methodological preferences, such as accessibility and proximity focused, will limit the policy impacts that favor one region over others [11,12].

Markusen classified various types of fuzziness. The concepts can be fuzzy simply because they are bad concepts or based on different audiences [11,12]. She also mentioned the unintentional fuzziness due to a political and market power to influence the narrative. She provided an example of the concept of "sustainability" as a political bias [11,12]. However, the author did not outrightly reject the work carried out since the mid-1980s. Instead, she emphasized that researchers pay attention to the fuzziness of concepts. She also agreed that these concepts may develop and mature over time but that it is equally possible to be distracted from the core issues in finding an appropriate solution [11,12].

Markusen relies mainly on her belief that institutions, actors, and behaviors are the key drivers of an urban environment. She argued that the overemphasis on the process alone, as practiced, led to a disconnect from the political and policy advocacy [11,12]. Therefore, she emphasized the inclusion of political, policy, and planning dimensions into regional studies, greater conceptual clarity, and increased depth of relevant evidence [11,12].

Markusen also highlighted several motivations behind these approaches. Primarily these motivations are based on the researcher's approach and methods in conducting the research, such as choosing qualitative case studies to avoid statistical analysis, representation, and generalizability $[11,12]$. She further highlighted that the choice of methods influenced by operational, resource, and accessibility constraints could affect the output quality. She provided 
Table 1 Fuzzy concepts in regional studies

\begin{tabular}{lll}
\hline $\begin{array}{l}\text { Conceptual Approach } \\
\text { (Contestation) }\end{array}$ & $\begin{array}{c}\text { Empirical Evidence } \\
\text { (Relevance and Quality) }\end{array}$ & $\begin{array}{l}\text { Policy Application } \\
\text { (Operationalization) }\end{array}$ \\
\hline Fuzziness & Vague evidence & Lack of integration \\
\hline Lack of clarity & Data availability & Ignoring relationships \\
\hline Theoretical evolution & Data quality & Interdisciplinary compatibility \\
\hline Industry relevance & Data bias - political influence & Inconsistency \\
\hline Bias-political/market & Research operational constraints & \\
\hline Bias-researcher & Preference of study area & \\
\hline Methodological preference & & \\
\hline Source: Adopted from Markusen (2003) [11,12]
\end{tabular}

an example of differences in the researcher's conclusion while studying the same phenomena, such as cooperative competition. Differentiating outcomes might result from ignoring certain actors or behaviors that could have a significant impact on the system $[11,12]$. Table 1 presents a summary of her arguments.

\section{The old debate}

Responding to Markusen's critique, Gernot Grabher and Robert Hassink initiated a public debate [13]. They invited researchers from regional studies to respond to her contributions. Consequently, this article reviewed three significant contributions from Arnoud Lagendiji, Jamie Peck, and Ray Hudson. We have also included Markusen's preceding response to her critics. All three authors - Arnoud Lagendiji, Jamie Peck, and Ray Hudson - have praised her work by agreeing with most of her arguments, but they have also shown some reservations. There was a consensus on her methodological preference of a quantitative approach for developing theories [13-15].

Lagendijik agreed that the standards were slipping in the regional studies and pointed out the lack of academic standards of communication and knowledge sharing between the different fields [14]. Whereas Peck (2003) [15], to some extent, agreed that there was an overuse of qualitative methods, she did not agree with Markusen on the comparative uselessness of qualitative methods such as interviews. In contrast, Peck considered that many studies used interview methods quite responsibly. She also did not accept the intended and systematic shift in the methodological malpractices, as suggested by Markusen [15].

Similarly, both Hudson and Peck agreed to the methodological issues that needed critical review in the regional studies, but they did not outrightly reject the usefulness of a case study and qualitative research [13,15]. According to Hudson (2003) [13], Markusen's approach to political inclusion was "misconceived" (p.741). Both, traditional theory and political economy might achieve political inclusion [13]. Hudson did agree somewhat with Markusen on the definition of fuzziness; however, he did not agree with her emphasis on validity and replicability as the basis for establishing a "one-to-one" relationship between the concept and the evidence [13]. Similarly, Hudson agreed to her call for more inclusion and applicability of the theory. Still, he disagreed with her approach to differentiating between process and links to agents because the process itself is the specification of internal and external links [13]. Both Hudson and Peck appreciate Markusen's emphasis on the role of a concept. However, they further advocated emphasizing a contextual dependency and differentiating between the traditional and critical conception [13]. Additionally, Hudson argued that the analyst's responsibility is to conclude based on the context [13].

In her response to the above critiques, Markusen once again voiced her concern about the "growing contempt of empirical work" and the lack of interdisciplinary linkages [12]. Replying to Lagendijk's approach to inter-disciplinary communication, she argued that instead of selective use and exclusion of networking, a conversation should include stakeholders from practitioners, institutions, and communities [12]. She disagreed with the objection raised by all three critics on preferring the quantitative approach over the quantitative. Conversely, she intended to segregate the utility and the role of data between qualitative and quantitative methods [12]. She again questioned the reliability of the construction of data due to the lack of methodological explanation. She emphasized the usefulness of secondary institutional data while underlying her concern regarding the institutional influence and the researcher's motivations behind the data generation [12]. Markusen further clarified Hudson's misunderstanding about her approach 
towards replicability in the qualitative work. The qualitative work should be more transparent with improved standards like quantitative evidence [12].

\section{Summary of the debate}

Starting with Markusen's core argument of isolating research from the policy pressures will form a fuzzy concept that will lead to difficulty providing evidence [11,12]. A lack of evidence will lead to accepting a "fuzzy concept and misguided policy" [11,12], asking for studies with a contextual relationship to develop better policies. The growth and development of complex systems incorporate different social processes, interdisciplinary links, and differentiating disciplinary perspectives [16]. Therefore, a single facet approach will be unable to capture the continuously changing whole. As stated by various researchers, there is no one way and no need to establish a singular concept or theory for development. In this approach [10,16, 17], concept development seems to be a more evolutionary process to reach a conclusive theory or to make it operational, validating Markusen's call for collective action to deal with multidisciplinary fields such as regional studies.

Georgescu-Roegen's philosophy of the "arithmomorphic" and "dialectical" concepts distinguish these distinct and overlapping concepts [18]. However, a discretely distinct concept opposes the notion of an evolutionary process [19]. An evolutionary process may not be decomposed into discrete components by overlooking the interdependencies [18,20].

Although various fields of sciences have drawn results from each other, increasing isolation and departmentalization of multiple domains result in a "patchwork" of empirical investigation [20]. Markusen's point seems quite valid (i.e., concepts are a generic and mandatory part of the evolutionary process), but it is being compromised by academia due to different constraints and motivations.

A question raised by Pike, Rodriguez, and Tomaney (2011) [10]: "Does such a diverse and varied conceptual and theoretical backdrop allow academics and policymakers simply to pick the theories to suit their interests and justify their interventions?" (p.4). Instead, broad and interdisciplinary studies need to incorporate contested concepts by opening theoretical dialogues [10]. Similarly, Sheppard and Plummer (2007) [21] advocated for a diverse "engaged pluralism" for meaningful and inclusive regional studies (p.2545). This approach encourages the inclusion of multi-agent models and multi-dimensions of politics, power structures, and dimensions of local normative values to develop an inclusive framework for local and regional development.

In local and regional development, a context plays a crucial role in defining policy intervention, but, as noted by Beer (2008) [22], "not all growth strategies work in all circumstances" (p. 85 ). Whereas, in a geographic context, development and growth profile is highly dependent on aspirations, institutional and governance structure, and other strategic dimensions [10]. Edwards (2007) [23] advocated understanding shared characteristics to evaluate causes and solutions, "since they are increasingly integrated across borders and disciplines and revolve around common if differently-experienced patterns of change and the capacity to control it" ( $p$. 3). He emphasizes conceptual and methodological coherence, which was lacking in regional studies, highlighted by Markusen.

The theory of sustainability and sustainable development is one of the examples of theoretical evolution. Strangely, the concept of sustainability was considered a political buzz by Markusen. It might be because when Markusen wrote the article, the theory of sustainability was still undergoing academic scrutiny. However, in subsequent years, the conceptual evolution of sustainability has been quite evident. The concept of sustainable development has extended beyond its deep-rooted quantitative and economic focus to include social and environmental dimensions with a more qualitative approach towards human wellbeing [24,25]. Additionally, the initial unilateral approach of sustainability emphasizing the physical environment adopted a more cohesive approach by incorporating economic and social aspects of development [26,27]. As Morgan (2011) [28] said, "Despite its fuzziness as a concept, or perhaps because of it, the principle of sustainable development has resonated around the globe, being equally applicable in the global North as it is in the global South" (p. 87).

From the discussion above, we suggest two forms of fuzziness; inherited and bequeathed. Inherited fuzziness is misconceptualized by a researcher while studying the contextual configuration of a case under investigation. In contrast, bequeathed fuzziness is associated with methodological and perceptional ambiguities that influence the research process. Inherited fuzziness is embedded in the contextual configuration of a case under investigation, such as non-deterministic conditions associated with complex and dynamic circumstances. A researcher passes on bequeathed fuzziness due to methodological weaknesses and the researcher's bias 
that could influence the conceptual interpretation and the research outcome. The following section discusses the relevance of conceptual fuzziness to multidisciplinary qualitative research, theoretical evolution, and methodological development to address inherited and bequeathed fuzziness.

\section{Inherited fuzziness, theoretical evolution and method- ological development}

Fuzzy concepts primarily deal with uncertain conditions due to a variation of conditions and the lack of precision to evaluate and quantify. Such complexities, associated with multidisciplinary and multicriteria research, could influence the researcher's conceptual understanding of the matter under investigation. Fuzzy theories combined with multicriteria decision-making can address non-deterministic conditions to address uncertainties. Stojcic et al. (2019) [29] reviewed 108 papers published between 2008-2018 in sustainable engineering in urban development and energy-related fields. They concluded that decision-making research is primarily reliant on the theories of uncertainty (e.g., fuzzy sets, grey, and neutrosophic theories). The complexity of the integrated problems forces researchers to use more flexible and straightforward methods [29].

Zadeh (1965) [30] was the first to introduce the fuzzy set theory to address vague and uncertain information. The theory facilitated the representation of human knowledge, quantifying fuzzy information through rules and linguistic values. Later researchers, such as Pawlak (1982) [31], Atanassov (1986) [32], and Smarandache (1998) [33], further enhanced the conceptual approach to quantify qualitative variables, weighting criteria, ranking alternatives, membership criteria, and decision-making preferences. Various qualitative methods such as Qualitative Comparative Analysis (QCA) adopted fuzzy set theory successfully. This paper discusses QCA methodology in detail, including the basic concept, application, limitations, and best practices.

QCA is a methodological approach defining data analysis techniques to deal with conceptual vagueness and fuzziness [34]. QCA uses fuzzy set theories to combine cases and conditions to represent vague knowledge and quantify causal relationships to generalize the analysis $[4,8]$. Historically, QCA has been more popular in politics, business, economics, and sociology. However, since 2010, the methodology has gained attraction from other regional and energy planning [4] and sustainable development [5].

Comparative case analysis provides a robust interpretational base to address its complexity and contextual uniqueness [35]. QCA enables planners to draw lessons to facilitate evidencebased multilevel policy interventions [2,36]. QCA methodology sits well within complexity theory due to its sensitivity to context, bridging the gap between quantitative and qualitative analysis, and addressing the conjunctural causation [2].

However, some methodological concerns could impact the outcome of QCA methodology. QCA is sensitive to the configuration of cases and their conditions [34]. Additionally, outcomes' logical explanatory power and connection to case configurational conditions are the critical concerns of QCA methodology [37]. The interpretation of these relationships is subject to the researcher's description and understanding. Furthermore, understanding outcomes is also subject to the audience's relevance and knowledge [38].

QCA emphasizes methodological knowledge and the researcher's familiarity with the case and conditions under investigation [34]. It is also imperative to ensure the logic and relevance of the proposition [4]. Another critical aspect is the methodology, data reliability, and replicability. QCA recommends using multiple methods and multiple datasets to ensure the reliability of results [4]. Furthermore, a clear description of the methodological process, data processing, and analytical emphasis is necessary to ensure replication of the study [4,34]. Another important aspect is to maintain QCA qualitative focus. Researchers should avoid excessive use of quantitative statistical approaches not to lose the qualitative component of the QCA [34]. Schneider and Wagemann (2010) [34] have proposed standards of good practices for QCA adopting fuzzy sets. These standards are regenerated and presented in Table 2.

The objective of the standards developed by Schneider and Wageman (2010) [34] is to standardize the methodological process in qualitative comparative studies through validity, reliability, and replicability. Adopting standard practices of explicit case justification, prior knowledge, data calibration, data consistency and coverage, empirical justification, dialogue between idea and evidence, multiple outcomes, theoretical relevance, generality, and replicability can ensure the outcome [34]. Although it is impossible for every publication to meet the high standards proposed for QCA methodology, methodological consistency and quality awareness will facilitate standardized methodological practices [34].

The discussion above shows that significant work has addressed the configurational com- 
Table 2 The standards of good practices for QCA

\begin{tabular}{ll}
\hline Pre-conditions and Methodologies & Analysis and Presentation \\
\hline Multi-case and Multi-conditions & Analysis and Interpretation \\
Familiarity with cases and characteristics & Priority of analysis \\
Relevance & Multiple solution formula \\
Parameter selection & Choice of solution formula (center of interpretation) \\
Interpreting results & Occurrence and non-occurrence of the outcome \\
Valid causal relationships & Exploratory - Dialogue between ideas and evidence \\
Explicit and justified Selection and rejection, & Degree of complexity and precision \\
scope conditions, causal relationships & Logical equivalence \\
Balance between cases and conditions & Limited diversity \\
Explicit Justification & Link to the case and the theory \\
Multi-method and multi-data & Avoiding contradictory simplified assumptions \\
Causal relationships & Intimacy \\
Comparison similarities and differences & Avoiding overinterpretation \& superficial statistics \\
Description of methods used & Presentation \\
Sufficient and necessary conditions (Variables) & Case- and conditions-oriented aspects \\
Re-specification and adaption & Relationships \\
Calibration Quantification of conditions & Reflecting data and methodological structure \\
Appropriate threshold & Theoretical relevance \\
Consistency and Coverage & Generality and functional argument \\
Research and theoretical specificity & Narrating causal links \\
& Connection between empirical results and theory \\
& Providing datasets and solution formulas \\
& Providing consistency and coverage measures \\
\hline
\end{tabular}

Source: Adopted from Schneider and Wagemann (2010) [34]

plexities associated with the case study. Such methodologies can help reduce the conceptual fuzziness inherited due to the contextual complexity or the researcher's inability to interpret the configuration of the case under investigation. The fuzziness generated by the researcher's methodological approach and political bias, as highlighted by Markusen (2003) [11,12], is thoroughly reviewed in the next section. We will also review the adaptability of standard practices discussed above and their relevance to multidisciplinary and interdisciplinary qualitative studies in the next section.

\section{Bequeathed fuzziness and prevailing practices}

Energy and urban structure are highly integrated, and efficiency will vary with geography, urban size, urban design, land use, building design, urban design, transportation system, energy distribution system, and social behavior [39]. For instance, the connection between access to energy, poverty, and wellbeing is influenced by different aspects, such as available infrastructure, socioeconomic conditions, and local climate conditions. They make the connection highly contextualized and configurational [40]. Similarly, determinants of energy poverty vary with geographical scale due to its complex interaction with the social landscape, built infrastructure, natural environment, and institutions [41]. Research based on the analysis of a single energyrelated experience or intervention lacking spatial connection will lead to weak policies and plans [6]. Inefficient integration of energy and spatial planning affects the efficiency of policy designs [42].

Researchers have acknowledged uncertainty in the energy-related decision-making environment $[43,44]$. Uncertainties exist in selecting criteria, reliable weightage, and the relative balance between the variants [7]. Researchers [45,46] have endorsed adopting a multidisciplinary approach in research methodologies and theories to address complexities in decision making in a sociotechnical environment. However, limiting energy planning to sectoral research and ignoring energy-spatial research has led to a widening gap between theory and practice [6].

The transformation of research into practice is subject to theoretical and practical evolution through knowledge sharing and comparison of well-known procedures [47]. Lessons learned are essential for policy translation; however, valuable lessons are subject to good practices in research. Verweij (2019) [2] found that qualitative comparative research did not always follow good spatial planning research practices. We further discuss some of the research limitations that have dealt with the integrational and contextual complexity of interdisciplinary fields. Our focus is on the literature of conceptual and methodological vagueness and policy integration that could influence both the research outcome and the lessons bequeathed. 
The sources of conceptual vagueness identified by Markusen (2003) [11,12] revolve around conceptual and theoretical biases. Sociotechnical studies often rely on the configuration of conditions, and causal directions are often ambiguous. From the researcher's perspective, these ambiguities grow due to the methodological standards and the researcher's ideological perception. This professional ideology could lead to overconfidence and potential insensitivity to alternatives and counterarguments [48]. Clark and Winegard (2020) [48] evaluated the ideological influence of social studies and highlighted two types of favoritism: methodological and ideological. Methodological and ideological bias influences the researcher's selective exposure and selective avoidance [48]. Ideological influence inherited from professional closeness influences the researcher's preferences and valuation, leading to a distortion of reality, invalid perception, and misleading outcomes [49]. Honeycutt and Jussim (2020) [50] further added that a political bias could deviate research objectives, distort facts, and mislead results. A masked interpretation can also gain prejudiced theoretical, methodological, and practical scoring by achieving specific ideological and political alignment [51].

Other primary concerns are exaggeration and stereotyping. The researcher's preferences, contextual narrative, selection of variables, and emphasis on selective outcomes will influence the results. For example, in racial studies, ignoring or controlling certain pre-existing conditions of the study groups (Stoet and Geary 2012) and misleading proxy measurements [52] will provide a misleading interpretation. Similarly, ignoring alternative hypotheses only because they will negate a particular group's beliefs leads to biased outcomes [48].

In another example, studies criticized Ewing and Rong's (2008) [53] work for selective exposure and ideological interpretation. Their research has used housing size, housing type, and density to statistically analyze the impact on energy consumption. Staley (2008) [54] and Randolph (2008) [55] reviewed the study regarding methodological and data legitimacy, interpretation, and ignoring critical factors. Randolph (2008) [55] indicated weakness in the data and methodology due to missing variables such as technological interventions, market-based alternatives, policy choices, household energy behavior, and other demographic factors such as quality of life and social choices. Randolph (2008) [55] further added that the conclusion derived through the selective use of variables and ignoring alternative hypotheses would be misleading for policy designs. For instance, the decisive conclusion that low-density houses are more energy-intensive and the recommendation of high-density development could be misleading [55].

Furthermore, Ewing and Rong framed their study from an environmental perspective [55]. Additionally, Staley (2008) [54] criticized the legitimacy of the methodology used and the conclusion drawn. The study's quantitative analysis based on unrelated data sets rendered their conclusions doubtful. Furthermore, they overlooked other crucial aspects such as travel behavior, housing envelops, and appliances energy performance. Alternative methodological options such as engineering analysis could show more meaningful results. Descriptive analysis with an absolute statement is also misleading in the absence of a range of crucial factors such as house and household size, levels of efficiency, and behavior [54].

Schlogl and Stutz (2019) [56] pointed out methodological and data deficiencies, such as precision, accuracy, reliability, and spatial and temporal uncertainties in their reviews. Their work highlights multiple data discrepancies such as accidents under-reporting, damage estimation, and differences in reporting through the use of numerous methods [56]. In another attempt to achieve methodological representativeness in assessing energy access, Seuret-Jimenez et al. (2020) [57] proposed a fuzzy logic methodology. However, their study was based on three variables - transport, cooking fuel, and electricity expenditure - while ignoring socioeconomic, environmental, and behavioral factors. Furthermore, using a single data source and a single unit of measurement completely neglected the possible data reporting discrepancies and alternative units that may have shifted the focus. Although the study has acknowledged the limitations, the decisive conclusion of achieving representativeness may not be justified, especially when fuzzy logic is highly sensitive to the configuration of conditions.

Multidisciplinary subjects, such as spatial and urban planning, urban resilience, and energy planning, require a system's approach and multicriteria evaluation to deal with sociotechnical uncertainties [45, 58]. However, methodological and scope inconsistency holds back any concluding argument about the relationship between intradisciplinary integration such as urban form and energy use [59] and integrated urban resilience [58]. Ko (2013) [59] reviewed the literature on methodological trends in evaluating the effects of urban form on energy use. He found a dominating behavior of prioritizing a simulation method over an experimental or statistical analysis. The methodology provided easy control on variables and less reliance on primary data. Similarly, Verweij and Trell (2019) [2], in their comprehensive literature review on spatial planning, found that the researcher's objective is often missing or vague.

In general practice, researchers spend 80 percent of their time cleaning data. However, most 
works fail to provide comprehensive information on methodologies adopted in data processing and their implications on the analysis [60]. Researchers have warned of using raw data without considering their characteristics and limitations that could lead to biased interpretation [56]. Furthermore, the lack of methodological and data processing descriptions will make it difficult for readers to assess the reliability of the process adopted and the quality of the outcome. This problem will make a study or a methodology impossible to replicate that would fail the objective of knowledge transfer and methodological evolution.

To assess the adoption of QCA best practices, as discussed in the previous section, Verweij and Trell (2019) [2] conducted a comprehensive literature review from the perspective of spatial planning research. They found that most of the studies had failed to comply with the criteria set by Schneider and Wagemann (2010) [34]. For instance, less than 50 percent of the studies had applied QCA in combination with other quantitative or qualitative methods; and only 42 percent had used multiple data types for calibration. Similarly, 58 percent of the studies did not analyze the necessity of the conditions was performed [2]. This failure reduces the clarity over research objective and contextual relevance [34]. The quality assessment of the studies was also quite difficult because nearly 42 percent of the studies did not report consistency scores.

Similarly, more than 70 percent had reported only one solution type, making it difficult to assess how they reached their conclusions [2]. Lack of descriptive evidence of multiple outcomes could lead to a wrong interpretation that may contradict the theoretical evidence [34]. According to Verweij and Trell's (2019) [2] review, over 50 percent of the studies failed to report the raw data. Additionally, vague or lack of information on calibration rules adopted in the study will further question the reliability of the data [2]. In this scenario, the quality of the data and the conclusion drawn will reduce the research reliability, validity, and replicability [34]. Although complete elimination of uncertainties is impossible, case configurational clarity, methodological best practices, and reporting description of data, and steps taken to process the data are very vital for knowledge transfer and utility [2,34]. Adherence to methodological best practices will ensure research quality and reduce the risk of bequeathing fuzziness.

In addition to bequeathed fuzziness, a theoretical inconsistency, methodological constraints, and ideological bias may not produce results capable of guiding policy design to solve contextspecific issues. For instance, most of the methods and frameworks considered in the resilience literature cannot assess the integrated urban system, nor may not be able to guide integrated decision making [58]. Similarly, Markusen (2013) [61] has criticized the indicators-based assessment due to its conceptual fuzziness and reliance on irrelevant proxy data. For example, in placemaking research, an evaluation based on research conducted in different circumstances and proxy data cannot justify the varying conditions. In addition to contextual variation, people's value judgment will also vary from place to place. Therefore, generalizing indicators based on case studies would not capture the dynamic socioeconomic structure and geographical variations [61]. She further added that it would be better to commit to honest evaluation with increased coordination and technical assistance. Generally, studies avoid tailored evaluations due to budget constraints [61], and any intervention lacking contextual connection may lead to a weak policy design [6]. However, the level of scope and complexity involved in multidisciplinary spatial studies requires knowledge to build on previously studied cases. Comparative studies can thus facilitate the knowledge sharing and translation of research into actions by evaluating contextual and operational similarities between cases. Furthermore, comparative studies built on historical knowledge will help to address scope and complexity challenges and address methodological and conceptual weaknesses in the multidisciplinary qualitative research $[2,47]$.

\section{Conclusion}

We would agree with Markusen's call for collective efforts and Grabher's approach to encouraging constructive linkage and dialogue to promote inclusive spatial studies rather than developing a singular solution $[12,19]$. Standalone studies, relying on an isolated context, may not be instrumental in resolving interrelated issues and contextual challenges of sustainable development [4]. Contextual variation, resource limitations, and institutional bias coupled with the discrete concepts and methodological discrepancies have undoubtedly influenced both past and present academic literature $[2,56,60]$. However, conceptual fuzziness does not stop the evolutionary process. For instance, the concept of sustainable development is one of the great examples that have evolved out of a limited scope of the environment and corporate social responsibility to a more cohesive principle of development equally applicable across the globe and generations [62]. However, a conceptual variation in sustainable development, due to contextual differences, operational constraints, and uncertainties in the decision-making process, poses a challenge for a standardized research methodology [63]. The methodological 
approaches in sustainable development and other multidisciplinary studies are going through an evolutionary process. In addition to methodological standards, another challenge posed by the credibility of the outcome has resulted from research produced under the influence of ideological bias, perception of choice, and prejudiced interpretation [48].

Political and operational interventions based on ideologically biased opinions would waste resources and create polarization. The negative consequences result in losing the public's confidence in expert knowledge and impartiality [48,64]. Honeycutt and Jussim (2020) [50] proposed a model to detect Ideological and political bias in research. Analyzing research questions, measuring bias, interpretation, repression of ideas and conclusions, influence on citations, and canonization of research findings are the model's bases [50]. Further complying with the best practices, researchers should enhance reliance on self creativity, consciousness, analysis, and adaptability, leading to the consistency of the mindful advancement of the methodological process $[34,48]$.

This review article has provided a comprehensive overview of the dominating practices in multidisciplinary qualitative research. As interpreted by Markusen (2003) [12], the conceptual fuzziness is due to the lack of clarity, relevance, and researcher bias. However, Stojcic et al. (2019) [29] also define fuzziness as uncertain conditions associated with the scope under research. For conceptual clarity, we need to differentiate between inherited and bequeathed fuzziness. Inherited fuzziness can come from non-deterministic states of the case under investigation, whereas methodological weaknesses and researcher bias create bequeathed fuzziness. The former has significantly evolved theoretically and methodologically, such as fuzzy concept theories and qualitative comparative studies. However, standardization of methodologies to address methodological vagueness still needs integrated efforts to overcome bequeathed fuzziness. The fuzziness produced due to lack of conceptual and methodological clarity, a paucity of explicit reasoning of choices, vague evidence, and the researcher's ideological bias could influence the quality of process adopted and results produced. Methodological weaknesses highlighted decades ago persist in interdisciplinary qualitative research. Despite efforts made to standardize qualitative research methodologies, such as the standards of good practices for QCA proposed by Schneider and Wagemann (2010) [34], the challenges of conceptual fuzziness continue to exist due to ideological bias, choice of inclusion and exclusion, operational constraints, data quality, and prejudice interpretation. Politically and professionally influenced research to achieve preconceived objectives can distort facts and mask interpretation [51] Recently, Honeycutt and Jussim (2020) [51] have proposed a model to detect systematic political bias in social science research. However, the model needs a comprehensive review of academic and publication standards and processes. For independent and cognitive evaluation of reality, it is necessary to keep researchers free from undue pressures exerted by institutions, peers, and superiors [48]. Hence, conceptual fuzziness needs to be addressed from both theoretical and ethical aspects. The recommendation is for unified methodological and ethical standards unanimously adopted by the academic community.

\section{References}

[1] Silva E, Healey P, Harris N, et al. Introduction: The Craft of Doing Research . In E. Silva, P. Healey, N. Harris, \& P. Broeck, The Routledge Handbook of Planning Research Methods, Abingdon, UK: Routledge, 2015.

[2] Verweij S and Trell E. Qualitative Comparative Analysis (QCA) in spatial planning research and related disciplines: A systematic literature review of applications. Journal of Planning Literature, 34(3): 300-317.

https://doi.org/10.1177/0885412219841490

[3] De Roo G and Silva E. A planner's encounter with complexity. Farnham, UK: Ashgate, 2010.

[4] Roig-Tierno N, Gonzalez-Cruz T and Llopis-Martinez J . An overview of qualitative comparative analysis: A bibliometric analysis. Journal of Innovation \& Knowledge, 2017, 2: 15-23. https://doi.org/10.1016/j.jik.2016.12.002

[5] Dang V, Wang J and Dang WVT. An integrated fuzzy AHP and fuzzy TOPSIS approach to assess sustainable urban development in an emerging economy. International Journal of Environmental Research and Public Health, 2019, 16: 2902. https://doi.org/10.3390/ijerph16162902

[6] Pascali PD and Bagaini A. Energy transition and urban planning for local development. A critical review of the evolution of integrated spatial and energy planning. MDPI, Open Access Journal, 2018 , 12(1): 1-21. https://doi.org/10.3390/en12010035

[7] Xu D. Sustainability prioritization of energy systems by developing an integrated decision support framework with hybrid-data consideration. Sustainable Energy Technologies and Assessments, 2020, 39: 100719 https://doi.org/10.1016/j.seta.2020.100719 
[8] Kaya I, Colak M and Terzi F. A comprehensive review of fuzzy multi-criteria decision making methodologies for energy policy making. Energy Strategy Reviews, 2019, 24: 207-228. https://doi.org/10.1016/j.esr.2019.03.003

[9] Arrizabalaga E, Munoz I and Hermoso N, et al. Methodology for the advanced integrated urban energy planning. Proceedings, 2019, 20: 17. https://doi.org/10.3390/proceedings2019020017

[10] Pike A, Rodrguez-Pose A and Tomaney J. Introduction: A handbook of local and regional development. In A. Pike, A. Rodriguez-Pose, \& J. Tomaney, Handbook of local and regional development, London: Routledge, 2011.

[11] Markusen A. Fuzzy Concepts, Scanty Evidence, Policy Distance: The Case for Rigour and Policy Relevance in Critical Regional Studies. Regional Studies, 2003, 37(6-7): 701-717. https://doi.org/10.1080/0034340032000108796

[12] Markusen A. On conceptualization, evidence and impact: A response to Hudson, Lagendijk, and Peck. Regional Studies, 2003, 37(6): 747-751. https://doi.org/10.1080/0034340032000108831

[13] Hudson R. Fuzzy concepts and sloppy thinking: Reflections on recent developments in critical regional studies. Regional Studies, 2003, 37(6): 741-746. https://doi.org/10.1080/0034340032000108822

[14] Lagendijk A. Towards conceptual quality in regional studies: The need for subtle critique-A response to Markusen. Regional Studies, 2003, 37(6): 719-727. https://doi.org/10.1080/0034340032000108804

[15] Peck J. Fuzzy old world: A response to Markusen. Regional Studies, 2003, 37(6): 729-740. https://doi.org/10.1080/0034340032000108813

[16] De-Paula S and Dymski G. Introduction. In S. a. Paula, Reimagining Growth: Towards a Renewal of Development Theory (pp. 3-26). London: Zed, 2005.

[17] Rowe JE. The importance of theory: Linking theory to practice. In J. E. Rowe, Theories of Local Economic Development: Linking Theory to Practice (pp. 3-27). Farnham: Ashgate, 2008.

[18] Georgescu-Roegen N. The Entropy Law and the Economic Process. Cambridge, MA.: Harvard University Press, 1971.

[19] Grabher G. Trading routes, bypasses, and risky intersections: Mapping the travels of 'networks' between Economic Sociology and Economic Geography. Progress in Human Geography, 2006, 30(2): $1-27$. https://doi.org/10.1191/0309132506ph600oa

[20] Whitehead AN. Modes of Thought. New York: Free Press, 1938.

[21] Sheppard E and Plummer P. Toward engaged pluralism in geographical debate. Environment and Planning A, 2007, 39(11): 2545-2548. https://doi.org/10.1068/a40205

[22] Beer A. The theory and practice of developing locally. In J. R. (Ed.), Theories of Local Economic Development: Linking theory to practice (pp. 63-89). Farnham: Ashgate, 2008.

[23] Edwards M. 2007, A world made new through love and reason: what future for 'development'? https://www.opendemocracy.net/globalization-institutions_government/world_reason_4566.jsp

[24] Geddes M and Newman I. Evolution and conflict in local economic development. Local Economy, 1999, 13(5): 12-25. https://doi.org/10.1080/02690949908726472

[25] Stimson R and Stough RR. Regional economic development methods and analysis: Linking theory to practice. In J. R. (Ed.), Theories of local economic development: Linking theory to practice (pp. 169-192). Farnham: Ashgate, 2008.

[26] Jonas AE, While AH and Gibbs DC. Carbon control regimes, eco-state restructuring and the politics of local and regional development. In A. Pike, A. Rodrguez-Pose, \& J. Tomaney, Handbook of Local and Regional Development (pp. 283-294). London: Routledge, 2011.

[27] Christopherson S. Green dreams in a cold light. In A. Pike, A. Rodrguez-Pose, \& J. Tomaney , Handbook of Local and Regional Development (pp. 371-380). London: Routledge, 2011.

[28] Morgan K. The Green State: Sustainability and the power of purchase. In A. Rodrguez-Pose, J. Tomaney, \& A. Pike, In the Handbook of Local and Regional Development (pp. 87-96). London: Routledge, 2011.

[29] Stojcic M, Zavadskas E and Pamucar D et al. Application of MCDM Methods in Sustainability Engineering: A Literature Review 20082018. Symmetry, 2019, 11(3): 1-24. https://doi.org/10.3390/sym11030350

[30] Zadeh L. Fuzzy sets. Information and Control, 1965, 8(3): 338-353. https://doi.org/10.1016/S0019-9958(65)90241-X

[31] Pawlak Z. Rough Sets. International Journal of Computer \& Information Sciences, 1982, 11(5): 341-356. https://doi.org/10.1007/BF01001956

[32] Atanassov K. Intuitionistic fuzzy sets. Fuzzy Sets and Systems, 1986, 20(1): 87-96. https://doi.org/10.1016/S0165-0114(86)80034-3

[33] Smarandache F. Neutrosophy: neutrosophic probability, set, and logic: analytic synthesis \& synthetic analysis. Santa Fe, NM, USA: American Research Press, 1998.

[34] Schneider C and Wagemann C. Standards of good practice in qualitative comparative analysis (QCA) and fuzzy-sets. Comparative Sociology, 2010, 9: 397-418. https://doi.org/10.1163/156913210X12493538729793 
[35] Ragin C. The comparative method: Moving beyond qualitative and quantitative strategies. Berkeley: University of California Press, 1987.

[36] Hamidov A, Thiel A and Zikos D. Institutional design in transformation: A comparative study of local irrigation governance in Uzbekistan. Environmental Science \& Policy, 2015, 53(B): 175-191. https://doi.org/10.1016/j.envsci.2015.06.012

[37] Jordan E, Gross E, Javernick-Will A, et al. Use and misuse of qualitative comparative analysis. Construction Management and Economics, 2011, 29(11): 1159-1173. https://doi.org/10.1080/01446193.2011.640339

[38] Gerrits L and Verweij S. The evaluation of complex infrastructure projects: A guide to qualitative comparative analysis. Cheltenham, UK: Edward Elgar, 2018.

[39] Ratti C, Baker N and Steemers K. Energy Consumption and Urban Texture. Energy and Buildings, 2005, 37(7): 762-776. https://doi.org/10.1016/j.enbuild.2004.10.010

[40] Jessel S, Sawyer S and Hernandez D. Energy, poverty, and health in climate change: A comprehensive review of an emerging literature. Frontiers of Public Health, 2019, 7: 357. https:///doi.org/10.3389/fpubh.2019.00357

[41] Mashhoodi B, Stead D and Timmeren AV. Spatial homogeneity and heterogeneity of energy poverty: a neglected dimension. Annals of GIS, 2019, 25(1): 19-31. https://doi.org/10.1080/19475683.2018.1557253

[42] Zanon B and Verones S. Climate Change, Urban Energy and Planning Practices: Italian Experiences of Innovation in Land Management Tools. Land Use Policy, 2013, 32: 343-355. https://doi.org/10.1016/j.landusepol.2012.11.009

[43] Zavadskas E, Govindan K, Antucheviciene J, et al. Hybrid multiple criteria decision-making methods: a review of applications for sustainability issues. Economic Research-Ekonomska Istraivanja, 2016, 29(1): $857-887$. https://doi.org/10.1080/1331677X20161237302

[44] Wu Y, Xu C and Zhang T. Evaluation of renewable power sources using a fuzzy MCDM based on cumulative prospect theory: A case in China. Energy, 2018, 147: 1227-1239. https://doi.org/10.1016/j.energy.2018.01.115

[45] Gore J, Ward P, Conway G, et al. Naturalistic decision making: navigating uncertainty in complex sociotechnical work. Cognition, Technology \& Work, 2018, 20: 521-527. https://doi.org/10.1007/s10111-018-0531-X

[46] Mosier K, Fisher U, Hoffman R, et al. Expert professional judgments and "naturalistic decision making". In K. Ericsson, R. Hoffman, A. Kozbelt, \& M. Williams, The Cambridge handbook of expertise and expert performance, 2nd ed. (pp. 453-475). Cambridge: Cambridge University Press, 2018.

[47] Booth P. What Can We Learn from France? Some reflections on the methodologies of cross-national research. In E. Silva, P. Healey, N. Harris, \& P. Broeck, The Routledge Handbook of Planning Research Methods (pp. 84-96). New York: Routledge, 2014.

[48] Clark C and Winegard B. Tribalsim in war and peace: The nature and evolution of ideological epistemology and its significance for modern social science. Psychological Inquiry, 2020, 31(1): 1-22. https://doi.org/10.1080/1047840X.2020.1721233

[49] Cornwell J, Jago C and Higgins E. When group influence is more or less likely: The case of moral judgments. Basic and Applied Social Psychology, 2019, 41(6): 386-395. https://doi.org/10.1080/01973533.2019.1666394

[50] Honeycutt N and Jussim L. A Model of Political Bias in Social Science Research. Psychological Inquiry, 2020, 31(1): 73-85. https://doi.org/10.1080/1047840X.2020.1722600

[51] Jussim L, Crawford J, Anglin S, et al. Interpretations and methods: Towards a more effective selfcorrecting social psychology. Journal of Experimental Social Psychology, 2016, 66: 116-133. https://doi.org/10.1016/j.jesp.2015.10.003

[52] Reyna C. Scale creation, use, and misuse: How politics undermines measurement . In J. Crawford, \& L. Jussim, Politics of social psychology (pp. 81-98). New York: Psychology Press, 2018.

[53] Ewing R and Rong F. The impact of urban form on US residential energy use. Housing policy debate, 2008, 19(1): 1-30. https://doi.org/10.1080/10511482.2008.9521624

[54] Staley S. Missing the forest through the trees? Comment on Reid Ewing and Fang Rong's "The impact of urban form on US residential energy use". Housing Policy Debate, 2008, 19(1): 31. https://doi.org/10.1080/10511482.2008.9521625

[55] Randolph J. Comment on Reid Ewing and Fang Rong's 'The impact of urban form on US residential energy use'. Housing Policy Debate, 2008, 19(1):45. https://doi.org/10.1080/10511482.2008.9521626

[56] Schlogl M and Stutz R. Methodological considerations with data uncertainty in road safety analysis. Accident Analysis and Prevention, 2019, 130: 136-150. https://doi.org/10.1016/j.aap.2017.02.001

[57] Seuret-Jimenez D, Robles-Bonilla T and Cedano K. Measurement of energy access using fuzzy logic. Energies, 2020, 13(12): 3266 https://doi:10.3390/en13123266 
[58] Fu X and Wang X. Developing an integrative urban resilience capacity index for plan making. Environment Systems and Decisions, 2018, 38: 367-378.

https://doi.org/10.1007/s10669-018-9693-6

[59] Ko Y. Urban form and residential energy use: A research of design principles and research findings. Journal of Planning literature, 2013, 28(4): 327-351. https://doi.org/10.1177/0885412213491499

[60] Wickham H. Tidy data. Journal of Statistical Software, 2014, 59(10): 1-23. https://doi.org/10.18637/jss.v059.i10

[61] Markusen A. Fuzzy concepts, proxy data: why indicators would not track creative placemaking success. Internal Journal of Urban Sciences, 2013, 17(3): 291-303. https://doi.org/10.1080/12265934.2013.836291

[62] Bansal P and Song HC. Similar but not the same: Differentiating corporate responsibility from sustainability. Academy of Management Annals, 2017, 11(1): 105-149. https://doi.org/10.5465/annals.2015.0095

[63] Verma P and Raghubanshi A. Urban sustainability indicators: Challenges and opportunities. Ecological Indicators, 2018, 93: 282-291. https://doi.org/10.1016/j.ecolind.2018.05.007

[64] Nichols T. The death of expertise: The campaign against established knowledge and why it matters. New York: Oxford University Press, 2017. 